\title{
Conditional Beta-Convergence by Gravity
}

\author{
Nico Stoeckmann \\ International Economics and Macroeconomics, Faculty of Business Administration and Economics, Paderborn University, \\ Paderborn, Germany \\ Email: nico.stoeckmann@upb.de
}

How to cite this paper: Stoeckmann, N. (2022). Conditional Beta-Convergence by Gravity. Theoretical Economics Letters, 12, 98-110.

https://doi.org/10.4236/tel.2022.121006

Received: December 12, 2021

Accepted: February 5, 2022

Published: February 8, 2022

Copyright (C) 2022 by author(s) and Scientific Research Publishing Inc. This work is licensed under the Creative Commons Attribution International License (CC BY 4.0).

http://creativecommons.org/licenses/by/4.0/ (c) (i) Open Access

\begin{abstract}
Globalization and the international interdependence of states have reached their climax at the beginning of the 21st century. At the same time, growing inequalities between and within countries are leaving some behind. While a variety of models have sufficiently explained national divergence, international divergence still remains subject of numerous studies. This work contributes to the set of possible explanations for worldwide disparities by combining the ideas of classical growth theory with the gravity model of trade. The circular relations between GDP, trade flows and TFP then explain long term differences in the development of states. Resulting path dependencies thus can be explained by an International Innovation Spiral that continuously leads developed economies towards potential higher outputs while existing alongside national peculiarities. In this way, the importance of trade unions and the openness to international markets can be theoretically further substantiated.
\end{abstract}

\section{Keywords}

Growth, Trade, TFP, Inequality, Conditional Beta-Convergence, Gravity Model

\section{Introduction}

Even if globalization has resulted in countries being more closely connected than ever before, there are some that have benefited little or not at all. While there are many explanations for national inequalities and their implications, the literature on theoretical justifications for international divergences is still growing.

In the past, there have been a variety of models that predicted beta-convergence where developing countries would catch up through the more efficient use of capital. When this could not be empirically observed for most of the countries considered, the failure to catch up was justified by either conditional beta-convergence 
or a path dependence. However, path dependence has been like a black box to the growth literature while conditional beta-convergence just generally states that the catch-up in growth is related to additional factors mostly leading to club-convergence within a homogeneous group of states.

Since both approaches are rather imprecise, this study aims to put such pathways or conditional-beta convergences into the proper context. Therefore, three of the most important indicators of macroeconomics-Gross Domestic Product (GDP), Total Factor Productivity (TFP) and multilateral trade-are combined. The relationship between trade and GDP is already described by the gravity model. Looking at this model's implications in detail reveals the reciprocal relation between production and trade. A larger GDP comes with larger markets and production possibilities, which increase trade, while at the same time exports and imports increase GDP in the long run. In order to define this sequence of effects more clearly, TFP is introduced as a mediator, which increases the more it is traded due to spill-over and competition effects. The result is a spiraling path on which countries continuously reach higher output, technologies and total trade.

This International Innovation Spiral does not rule out any national effects, especially not the higher efficiency in the use of capital. They exist side by side, whereby the capital effect can lead countries to rise to a group in which they can benefit from the innovation spiral more efficiently. The combination of this capital efficiency with the openness of the markets then leads to long-term, self-sustaining growth. If this cannot be guaranteed in all countries, it could mean that the gap between rich and poor states will most certainly widen. High income countries (HIC) would dominate world markets and become an even smaller closed club.

There are already some options to integrate low income countries (LIC) globally, so that they can establish themselves on world markets. This study predicts which of them will be successful in the long run and also explains a part of China's disproportionate growth in recent years. The strong discrepancy to the other, especially to the remaining BRICS (Brazil, Russia, India, China, South Africa) states can thus be partially justified and does not have to continue to be regarded as an anomaly of economic models.

For this reason, the individual relationships between GDP growth, total trade and TFP are discussed based on already existing economic theories and recent literature in section two. Then the model and its implications are derived by piecing together the puzzle resulting in the International Innovation Spiral in the third section before section four concludes.

\section{Growth, Trade and TFP}

Former United Nations-secretary Kofi Annan once stated that "open markets offer the only realistic hope of pulling billions of people in developing countries out of abject poverty, while sustaining prosperity in the industrialized world" 
(United Nations, 2000). What was true in 2000 is now even more relevant in a world that is connecting and changing even faster. Unfortunately, decoupling does not only exist between east and west, but also between LIC and HIC. Even if globalization has mostly positive effects for many, it causes some to fall behind.

The economic growth literature on national inequalities provides several explanations, such as Kuznets' curve (1955). He was one of the first relating technological progress to wealth. His idea was that innovations first increase the level of inequality and while more people gain access to these new technologies, inequality decreases. It is analogical to the heterogeneity among states' economic growth rates. Countries have access to new technologies $A$ at different points in time. That is why economists are aware, not just since the Solow model (1956, 1957), that such technological differences can also lead to income divergence at the international level. After Solow himself and countless other authors tested and improved the model intensively over several years, the era of endogenous growth models came during the 1980s with approaches by Romer (1986) or Lucas (1988). Further subsequent models concentrated even more intensively on the endogenization of technological progress primarily taking closed economies into account and explaining the innovation growth of countries with the voluntary redistribution of workers from manufacturing to the Research and Development (R \& D) sector.

While these models explain a significant part of growth, most of them neglect advantages of an open economy. Trade and general global interaction are crucial and should therefore be taken as additional key factors in determining growth. Besides spill-over effects, innovations are mainly driven by substantial bigger markets.

The gravity model of trade already successfully links larger markets to more international connectivity. It indicates the intensity with which states interact by quantifying bilateral trade with the help of exogenous macroeconomic impact factors and geographical peculiarities. The fundamental determinants are equivalent to Newton's gravity, where the force of attraction between two bodies depends on the relation of their masses and the distance between them.

Among others, Anderson (1979), Bergstrand (1985) and then Anderson \& van Wincoop (2003) provide solid theoretical support for the gravity model of trade. Currently, this model dominates most of the trade-related literature. Although gravity is economically well founded and combines two essential variables of the economy: GDP and trade, there are no substantial studies that combine the implications of the model itself with other macroeconomic theories. The rationale for the relationship between these two variables is rather straightforward. Larger economies provide more resources and can therefore produce goods and services at a higher quantity. At the same time, larger economies are also associated with a higher potential for imports. Similar to Newton's model, the distance between the two economies considered is inversely proportional to the bilateral 
trade. Greater distances correspond to higher transport costs, which have an impact on individual trade decision-making processes.

A large number of follow-up studies and meta-papers in the field of international trade literature define Anderson's (1979) approach as the first theoretical foundation of the gravity model. Anderson (1979) derives international goods movements from country $i$ to country $j$ in an ideal world without restrictions as $X_{i j}$, which is proportional to the product of the two sizes of respective economies $Y_{i}$ and $Y_{j}$. He assumes that states have a differentiated output $Y$, preferences among the countries are homothetic and identical, prices are identical in all countries and that trade is in a multilateral equilibrium. The latter implies the market-clearing price. The assumptions lead to the fact that the state $j$ demands the goods of $i$ in proportion to its output. Thus $X_{i j_{\text {And }}}=b_{i} Y_{j}$, where $b_{i}$ represents the portion of good $i$ demanded by every importer in $j$. The market-clearing equilibrium price indicates that bilateral trade can be represented as $X_{i j_{\text {And }}}=Y_{i} Y_{j} / Y_{w}$, where $Y_{w}$ reflects the global output (Anderson, 1979). However, Anderson (1979) is not able to sufficiently implement transport costs. He assumes the convention that all free trade prices are identical.

Unlike Anderson (1979), Bergstrand (1985) includes prices and price indices in his derivation of the gravity model on both the theoretical and the empirical level. He assumes a constant-elasticity of substitution (CES) utility function based on Armington (1969) to show that products from different markets are imperfect substitutes. His derivation of the model is more complex and differentiated than Anderson's (1979), which on the one hand allows more detailed conclusions about the influencing factors of bilateral trade, but on the other hand limits the exact implementation in empirical estimations. There is also a simplified version of Bergstrand's (1985) model without any restrictions, the friction-less case. Trade flows between country $i$ and country $j$ are then also only dependent on the outputs of the respective countries and can be represented by $X_{i_{\text {Ber }}}=Y_{i}^{1 / 2} Y_{j}^{1 / 2}$ (Bergstrand, 1985; Stoeckmann, 2020).

Also with regard to further derivations of the gravity model such as Anderson \& van Wincoop's (2001), it can be stated that bilateral trade flows between country $i$ and $j T_{i j}$ can be defined as a general function of the two economic sizes $T_{i j}=f\left(Y_{i}, Y_{j}\right)$ and further country-pair specific peculiarities based on the chosen model. The total trade of a country in time point $t$ is therefore highly dependent on its own output

$$
T=f(Y)
$$

Larger economies thus have a higher trade volume than smaller. While the own output indisputably has a positive impact on trade, the impact of others' GDP is ambivalent. On the one hand both Anderson (1979) and Bergstrand (1985) multiply the numerator by the trading partner's GDP, while on the other hand Anderson (1979) implements the world's output $Y_{w}$ as a denominator. For now, only the simplified form, as in Equation (1), is considered. In the fur- 
ther analysis of this study, the positive impact of trading partners will also be discussed.

Larger trading volumes and, above all, more intensive networking at the international level inevitably lead to a growth in innovation through more competition and spill-over effects. Even the smallest inefficiencies in markets lead to distortions and misallocations, which in turn lead to an obstacle to TFP growth (Restuccia \& Rogerson, 2008). While Ades \& Glaeser (1999) or Frankel \& Romer (1999) find a causal effect of trade on TFP, Rodrik (2000), Rodriguez \& Rodrik (2000) and Irwin \& Terviö (2002) argue that trade is not a direct determinant of TFP if institutional strength and geographical peculiarities are included. Alcalá \& Ciccone (2004) find a significant and robust causal effect of trade on productivity across countries by using real openness as a measure of trade. Helpman (1988) even finds economies of scale in growth. According to him and previous studies (Bhagwati, 1978; Feder, 1983; Romer, 1986) GDP growth goes hand in hand with export growth. In the majority of cases, however, there is no unique causality found.

Grossman \& Helpman (1990) define trade as the engine of growth in one of their studies. First, the comparative advantage, according to Ricardo, determines in which direction states specialize and then Marshallian economies of scale in the respective specialized industry are assumed. They refer to Romer (1990), who defined innovation growth as non-diminishing economies of scale that ensure long term growth. There are also more recent studies that contribute to the relationship between innovation and trade including Eaton \& Kortum (2002), who use a dynamic Ricardian model to assign innovation to lower trade barriers and more intense international competition. They also propose to distinguish between technologies that are accessible to everyone and technologies that only industrialized countries can use. Hsieh \& Klenow (2010) summarize the results of previous studies and conclude that TFP has a strong impact on growth. They assume this influence to be at $50 \%-70 \%$. They even suggest that TFP growth attracts more capital and labor. The authors estimate this indirect accumulation effect to be bigger than the actual effect on output. Kucheryavyy et al. (2016) add Marshallian externalities to the Eaton \& Kortum (2002) framework to show heterogeneous degrees of specialization between industries.

In summary of the entire recent trade-TFP literature it can be stated that there are two dominant reasons why trade has a positive causal impact on innovation growth. On the one hand, larger international markets are associated with more competition for both domestic companies through imports and for exporting companies on the world market. On the other hand, there are spill-over effects for open economies, both cross-border intra-industry and national cross-industry. Countries that pursue an outward development policy therefore grow faster than isolated states.

Furthermore, there are some model theoretical assumptions that are successful over a variety of approaches. In most cases the basic structure of the chosen 
model is a Ricardian-Marshallian type. States first specialize on the basis of their comparative advantage and can then expect economies of scale in their chosen industries. These advantages are then defined via branch-specific TFP. In addition, a distinction between different types of availability of technologies is made. Therefore, it is useful to differentiate between exclusive technologies and technologies that are available to every state. Sometimes, the attraction of further production factors by a higher TFP is theoretically implemented by the choice of a more specific production function.

The general relationship between technological progress or innovation $A_{i}$ and trade in country $i$ can thus be represented as

$$
A=g(c, T) \text {. }
$$

The more a country is involved in international trade, the higher the innovation, either from the urge to withstand international markets, to expand its own position, or through network-related spill-over effects. Technological progress in country $i$ in time point $t$ is therefore a function $g$ of the commonly available technology in that period $c_{t}$ and the country's respective total trade in the previous period $T_{i_{t-1}}$. This delay of one period is included in order to be able to better fit actual $\mathrm{R} \& \mathrm{D}$ processes.

The last of the three relationships is the most straightforward. As previously stated, Hsieh \& Klenow (2010) estimate the individual effect of TFP on growth as $50 \%-70 \%$. The Solow residual represents the general efficiency of the respective country. It indicates what part of the growth in production cannot be traced back to an increase in the use of the production factors capital $K$ and labor $L$. Thus, GDP in country $i Y_{i}$ is generally defined by

$$
Y=h(A L, K) \text {, }
$$

a function $h$ of total factor productivity $A_{i_{t}}$, the capital stock $K_{i_{t}}$ and the available labor force $L_{i_{t}}$ in that respective country $i$ in time point $t$.

Many growth models, especially Solow based, initially predicted that developing countries will catch up in per capita income (PCI) through a more efficient use of capital. These convergences, beta-convergences, mean that economies with initially lower PCI tend to grow faster than countries with comparably higher PCI which in conclusion leads to a convergence in steady-states in the long run. However, convergences like these only take place within homogeneous groups of similar countries like within the Organisation for Economic Co-Operation and Development (OECD). The most obvious, but less popular explanation is based on the availability of technologies, which is higher in the OECD than in other countries due to the closer community of states. Other states do not seem to have access to same technologies. For this reason, there are multiple steady states within the international community. Against the background of advancing globalization, however, it is surprising that such a conditional beta-convergence can be observed. Despite perfect networking through the internet, technologies are not used uniformly worldwide. So where does this divergence come from? Some 
authors argue with path dependency. The idea of such paths dominated the literature on technological change for the last decades. However, this path dependency is only vaguely described and poorly justified. Some social studies argue that geographic conditions and resources paved a way to a successful economy. Since there are many countries that are among the leading industrial nations, which are relatively poor in commodities or had to face a complete shutdown of the economy during and after World War II, these arguments about peculiarities initiating a successful path seem rather uninspired.

A synthesis of Equations (1), (2) and (3) appears to be more promising. The resulting model allows to observe path dependencies, but does not need them as an underlying reason. Therefore, this study initially proposes an International Innovation Spiral that justifies the heterogeneous developments of countries quite intuitively.

\section{International Innovation Spiral}

Combining Equations (1), (2) and (3) indicates that GDP has a positive impact on trade, trade strengthens technological progress and thus more output is generated. Although there are additional impact factors, the GDP of country $i$ in time point $t Y_{i_{t}}$ can thus be defined as a nested function of the previous period's GDP

$$
Y_{i_{t}}=h\left\{g\left[f\left(Y_{i_{t-1}}\right)\right]\right\} .
$$

Consequently, an increase in the current GDP will also lead to more GDP in the future which is then reflected on individual path dependencies. But instead of having linear paths as it is often assumed in the literature, these relationships in Equation (4) can be sketched as in Figure 1 by an International Innovation Spiral (IIS). In contrast to the previous literature's black box with respect to path dependencies, the two variables trade $T$ and technological progress $A$ serve as

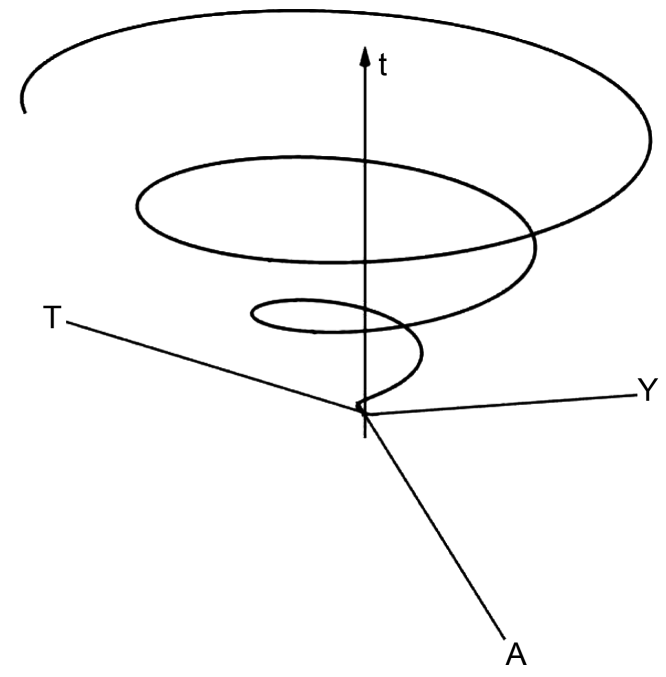

Figure 1. International innovation spiral. 
mediators that complete a circular movement towards higher outputs $Y$.

The IIS visualizes the previously derived dependencies in an intuitive manner. However, additional impact factors like the population growth or the national-specific efficiency in the use of capital, which classic models require, are not yet considered.

In this purist version as in Figure 1, different starting points would lead to a growing difference in the output of two countries if all other factors remain constant over time. The reason for this is that unequal outputs lead to changes in market shares, which in turn increase the technological advantage over the international markets for one country and decrease it for the other. Even if the IIS is not further specified, it can also be used for models in a Ricardian-Marshallian environment which then would justify growing scale effects for countries in specific comparatively advantageous industries. Formally, all variables of the Equations (1), (2) and (3) and of the resulting Figure 1 would then each have an index for the specific industry considered. Consequently, there would be coexisting spirals with national inter-industry effects between. Technological progress would then be allowed to spill from one IIS to another by extending Equation (2).

Two conjunctions of this circular movement through time are crucial for economies. On the one hand, it might be the case that the economic size $Y$ of some country is not sufficient to profit from the transmission of technological growth on international markets. On the other hand, it may be that larger markets do not stimulate more trade due to a lack in openness of the economy itself.

The size of the economy and the trade volume should not be seen in absolute terms, but rather be put in relation to other economies if it is about technological progress in international markets through competition. If a country is relatively small, it can lose touch with international competition and thus can only work with generally available technologies $c$. It would then find itself in a Technology Trade Trap in which the country would need a higher technological standard in order to survive in international markets, but at the same time also needs larger markets in order to develop technological progress from competition. Breaking out from this trap is difficult. Externally reintegrating those countries into the markets should be one straightforward solution to boost economic growth in even the poorest countries.

Contrary, already larger economies are expected to develop a growing output over a long period of time, from which a steadily growing technological advantage emerges. If this is combined with the opposite effects for the smaller, more isolated economies, a steadily growing international divergence can be deduced. Slight differences in the initial output can therefore lead to larger ones in the long run. In conclusion, the path dependency that is propagated in many studies can thus partly be observed, but should not be seen as a reason, rather as a symptom.

The longer the period considered, the more low output countries would be left 
behind until a point where they are completely irrelevant to international markets and only rely on the commonly available technologies. If it is additionally assumed, as many previous studies have done, that a higher TFP would attract more factors of production, economies could shrink not only in relevance, but also in absolute terms resulting in labor and capital outflows. An early intervention is therefore crucial and should be the goal to allow LIC to continue to benefit from technological progress through international markets. Both protectionism on the side of the LIC and exclusion in trade organizations on the side of HIC are therefore hindrances for stable long term growth.

Intra-HIC trade is robust and will continue to be used as a catalyst for innovation. Global technological progress depends, by definition, on how large the markets are, therefore, how many countries are included. From a development policy point of view, a stronger integration of LIC into world trade makes more sense than leaving states behind and then providing them with external help. From the LIC point of view, this innovation spiral can be seen as an incentive to integrate oneself even more into world trade, or to allow to be integrated via trade unions or free trade agreements.

With the ongoing COVID-19 pandemic, countries all over the globe experience a range of negative effects. Developed, more networked countries are initially more affected than developing countries and are experiencing declines in their GDP, which in absolute terms are greater than those of developing or emerging countries. Although HIC experience serious cuts for life, it can also be seen as an opportunity for LIC to make catching up on world markets easier, because some paths have been slightly reset. The goal should be to support LIC in the fight against the pandemic, so that on the one hand the humanitarian impact is kept within limits and on the other hand the economic cut is comparatively smaller and a K-recovery can be averted. Should such aid fail or should the pandemic become even more intense in these countries, it becomes increasingly unlikely that those countries will ever catch up gaining technological progress through international markets.

It can also be discussed to what extent such an integration of LIC should look like from the HIC viewpoint. It is difficult to justify why subsidies for imports from LIC should effectively improve technological growth in the exporting country. With respect to Equation (2), the impact of trade on technological progress would then be lowered or even erased by noncompetitive prices.

The BRICS countries in particular have been the focus of convergence in growth-related studies since the beginning of the new millennium. It has long been assumed that these countries will catch up with leading industrial nations through technology spillovers and the more efficient use of capital. However, it can be stated that so far only China has been able to break away from this group and connects economically with the industrialized west.

Emerging economies, by definition within the LIC-HIC scale, can take away important implications from the IIS. China appears to have taken significant 
steps to embark on a successful path while the other members of the BRICS still struggle to establish their positions on the world market. It would be unsatisfactory to label China, as in many studies, a special case that cannot be captured with current models. Even though China can consider itself to be profiting sufficiently from the international exchange as in the IIS, there were initial national impact factors that got the country on track. The Chinese government took substantial steps to even start this process. Sticking to classical growth models, such as Solow's, the more efficient use of capital and an increased savings rate played a significant role with respect to the Chinese growth miracle allowing them to jump onto the next technology growth level where the club of industrialized nations is located. Also the over-proportional population size contributed indirectly as it is part of the general output function (3). These national factors do not contradict the idea of the IIS, this example rather shows the difference between national and international effects, which can coexist and even substitute each other in the short run. In the long run, however, national peculiarities are fading out while the countries developing through a spiraling growth.

The model even allows for more specifications. Equation (1) only generally defines trade in relation to an unspecific output while gravity models of both Anderson (1979) and Bergstrand (1985) suggest a more precise implementation. To measure bilateral trade flows, they also take GDP of trading partners into account. Converting this into the set-up presented could result in $T_{i}=f\left(Y_{i} \cdot \sum Y_{i n}\right)$ with $n=1, \cdots, N$, where $N$ is is number of trading partners. This definition intensifies the potential problems arising from the trap in which developing and emerging countries can find themselves in. If closed clubs would become literal, the divergence would even increase further.

The idea of the IIS resulting in individual levels of technological and economic growth can be applied to the whole bandwidth of growth theories. Wherever technological progress is integrated as an exogenous variable, the IIS can coexist with national effects. In the classic Solow model thus a country can find a connection to international markets through a higher savings rate or a higher capital-labor ratio in the short-run. In technology-endogenous models, such as Romer's (1990), on the other hand, processes can be justified even better using the spiral. The reallocation of a share of the workforce is therefore not voluntary, but serves to maintain or to increase competitiveness on international markets.

\section{Conclusion}

Combining GDP $Y$, trade $T$ and technological progress $A$ derives an International Innovation Spiral, which can explain a significant part of conditional beta-convergence between countries. Assumptions from existing models were adopted for the relationships between the individual variables. Total trade $T$ is proportional to the output $Y$ based on the gravity model, technological progress $A$ is proportional to the total trade and the output is in turn proportional to the technological progress. Countries that are in close contact with the international 
community, above all with the industrialized nations, move over the time axis in ever larger cycles across the three variables while shaking off other nations on global markets. If the divergence between HIC and LIC is too large, LIC can no longer benefit from international markets and thus become irrelevant for trade.

What would further intensify this effect would be a more specific production function that makes the input factor accumulation dependent on the technological progress. Because the aggregation of production factors can be based on input allocation efficiency, it would also be justified why developing countries experience exponential capital outflows and outflows of labor, a brain drain through labor migration. Since, mostly outside classic economic theory, state funding can be essential in supporting technological progress, more available capital also leads to extra kick-off financing for innovations.

Another, more ambivalent, implication of the IIS is the impact of population on economic growth. Due to a higher population growth, per capita income naturally decreases in the short term. In the long run, however, an increase in the population could also lead to a higher per capita income since labor is also part of the output function. Through the IIS, the connection of an economy to the international community of states can then be achieved through larger markets, which in the following periods leads to greater technological and thus resulting in higher economic growth rates in comparison to population growth. China is one of the countries that, in addition to a higher savings rate and other individual political measures, was able to benefit from this factor and is therefore of great relevance on international markets due to its economic and population size.

Population growth consequences and also some further suggestions might be controversial. The extent to which national effects can be weighed against international is not clearly defined. Also the relationship between the generally available technological progress and the progress resulting from international competition has not yet been specified. Due to the generalization of this work, all these ambiguities could, nonetheless, be implemented in specific models.

The spiral theoretically implies a potential dark future for the world economy. Because national peculiarities are becoming increasingly insignificant and industrial nations benefit exponentially more from international markets, a phenomenon corresponding to Newton's gravity model could be predicted. Only a few economies will stand out from the rest and absorb market shares and resources from others. If a long time horizon is considered, it can even be assumed that more and more of this closed club of the remaining nations will fall off the international market and that their remains will be absorbed by the dominant economy like in a literal black hole.

This dystopian scenario underlines the importance of trade unions from a theoretical perspective. To appear as an economic unit, for example as the European Single market does, increases participation and thus technological progress due to the simple economic size. So, from this point of view, Britain's exit was bad for both parties. In many ways the European Union appears as a unit in 
which technologies are transferred transparently within, similar to China or the USA. The global dominance of these three economic powers will continue to grow in the future due to their size, but also due to the second important factor of the gravity model-the distance. Because these political and economic powers are geographically distributed across the globe, clusters and thus geographically dependent beta-convergences will continue to form.

In addition to the importance of the trade unions, further political recommendations for action can be derived. The aim should be to guarantee more competition without monopolies, to promote privatization in as many markets as possible and to support developing countries in their short-term national efforts to participate from international markets without being subsidized.

\section{Conflicts of Interest}

The author declares no conflicts of interest regarding the publication of this paper.

\section{References}

Ades, A. F., \& Glaeser, E. L. (1999). Evidence on Growth, Increasing Returns, and the Extent of the Market. The Quarterly Journal of Economics, 114, 1025-1045. https://doi.org/10.1162/003355399556205

Alcalá, F., \& Ciccone, A. (2004). Trade and Productivity. The Quarterly Journal of Economics, 119, 613-646. https://doi.org/10.1162/0033553041382139

Anderson, J. E. (1979). A Theoretical Foundation for the Gravity Equation. The American Economic Review, 69, 106-116. https://doi.org/10.1177/000841747904600316

Anderson, J. E., \& Van Wincoop, E. (2003). Gravity with Gravitas: A Solution to the Border Puzzle. The American Economic Review, 93, 170-192. https://doi.org/10.1257/000282803321455214

Armington, P. S. (1969). A Theory of Demand for Products Distinguished by Place of Production. Staff Papers, 16, 159-178. https://doi.org/10.2307/3866403

Bergstrand, J. H. (1985). The Gravity Equation in International Trade: Some Microeconomic Foundations and Empirical Evidence. The Review of Economics and Statistics, 67, 474-481. https://doi.org/10.2307/1925976

Bhagwati, J. N. (1978). Appendix to "Anatomy and Consequences of Exchange Control Regimes”. In Anatomy and Consequences of Exchange Control Regimes (pp. 219-221). NBER.

Eaton, J., \& Kortum, S. (2002). Technology, Geography, and Trade. Econometrica, 70, 1741-1779. https://doi.org/10.1111/1468-0262.00352

Feder, G. (1983). On Exports and Economic Growth. Journal of Development Economics, 12, 59-73. https://doi.org/10.1016/0304-3878(83)90031-7

Frankel, J. A., \& Romer, D. H. (1999). Does Trade Cause Growth? The American Economic Review, 89, 379-399. https://doi.org/10.1257/aer.89.3.379

Grossman, G. M., \& Helpman, E. (1990). Trade, Innovation, and Growth. The American Economic Review, 80, 86-91.

Helpman, E. (1988). Growth, Technological Progress, and Trade. Empirica, 15, 5-25. https://doi.org/10.1007/BF02249183 
Hsieh, C. T., \& Klenow, P. J. (2010). Development Accounting. American Economic Journal: Macroeconomics, 2, 207-223. https://doi.org/10.1257/mac.2.1.207

Irwin, D. A., \& Tervi, M. (2002). Does Trade Raise Income? Evidence from the Twentieth Century. Journal of International Economics, 58, 1-18. https://doi.org/10.1016/S0022-1996(01)00164-7

Kucheryavyy, K., Lyn, G., \& Rodrguez-Clare, A. (2016). Grounded by Gravity: A WellBehaved Trade Model with Industry-Level Economies of Scale (No. w22484). National Bureau of Economic Research. https://doi.org/10.3386/w22484

Kuznets, S. (1955). Economic Growth and Income Inequality. The American Economic Review, 45, 1-28.

Lucas Jr., R. E. (1988). On the Mechanics of Economic Development. Journal of Monetary Economics, 22, 3-42. https://doi.org/10.1016/0304-3932(88)90168-7

Restuccia, D., \& Rogerson, R. (2008). Policy Distortions and Aggregate Productivity with Heterogeneous Establishments. Review of Economic Dynamics, 11, 707-720. https://doi.org/10.1016/j.red.2008.05.002

Rodriguez, F., \& Rodrik, D. (2000). Trade Policy and Economic Growth: A Skeptic's Guide to the Cross-National Evidence. NBER Macroeconomics Annual, 15, 261-325. https://doi.org/10.1086/654419

Rodrik, D. (2000). Institutions for High-Quality Growth: What They Are and How to Acquire Them. Studies in Comparative International Development, 35, 3-31. https://doi.org/10.1007/BF02699764

Romer, P. M. (1986). Increasing Returns and Long-Run Growth. Journal of Political Economy, 94, 1002-1037. https://doi.org/10.1086/261420

Romer, P. M. (1990). Endogenous Technological Change. Journal of Political Economy, 98, S71-S102. https://doi.org/10.1086/261725

Solow, R. M. (1956). A Contribution to the Theory of Economic Growth. The Quarterly Journal of Economics, 70, 65-94. https://doi.org/10.2307/1884513

Solow, R. M. (1957). Technical Change and the Aggregate Production Function. The Review of Economics and Statistics, 39, 312-320. https://doi.org/10.2307/1926047

Stoeckmann, N. (2020). Recalculating Gravity: A Correction of Bergstrand's 1985 Frictionless Case. Econ Journal Watch, 17, 333-337.

United Nations Secretary-General (2000). A New Coalition for Universal Values. https://www.un.org/sg/en/content/sg/articles/2000-07-26/new-coalition-universal-values 